\title{
Semi-Solid Processing of Powder Steels in Cryogenically-Cooled Die MASEK Bohuslav ${ }^{1,}$, AISMAN David ${ }^{1, b}$, RUBESOVA Katerina $^{1, \mathrm{c}}$, JIRKOVA Hana ${ }^{1, d}$
}

\author{
${ }^{1}$ University of West Bohemia in Pilsen, Research Centre of Forming Technology - FORTECH, \\ Univerzitni 22, 30614 Pilsen, Czech Republic \\ amasekb@kmm.zcu.cz, ${ }^{\mathrm{b}}$ daisman@vctt.zcu.cz, ${ }^{\mathrm{c} k a t k a . r u b e s o v a @ c e n t r u m . c z,}{ }^{\mathrm{d}} \mathrm{h} . j \mathrm{j}$ irkova@email.cz
}

Keywords: mini-thixoforming, powder steel, CPM, semi-solid, undercooled die

\begin{abstract}
By processing steels in the semi-solid state it is possible to achieve unconventional structures even with commonly used steels. This can be demonstrated on X210Cr12 tool steel. After semi-solid state processing, $96 \%$ of the microstructure can consist of metastable austenite. In the microstructure, there are polyhedral grains embedded in a ledeburitic network. A combination of semi-solid state processing and rapid solidification is a new method for modifying the microstructure more substantially. In the present experiment, two tool steels, CPM 15V and CPM S30V, were processed by an unconventional method. Since the steels are made by powder metallurgy, their initial structure contains globular carbides in ferritic matrix. Both materials have high levels of carbon and alloying elements, namely vanadium and chromium. The unconventional processing was carried out by mini-thixoforming which enables the use of a small amount of metal. After heating into the semi-solid region, the material was rapidly forced by lateral extrusion into a cavity of a metal die where rapid solidification and rapid cooling took place. Two cooling schedules were employed. In the first case, the die was at room temperature, whereas in the second one it was pre-cooled to $-196^{\circ} \mathrm{C}$ using liquid nitrogen. Since the test sample was cooled from both sides and its thickness was $3 \mathrm{~mm}$, immensely high cooling rates were achieved. The influence of the cooling rate was also noticeable in the microstructures containing high fractions of metastable austenite, martensite and carbides.
\end{abstract}

\section{Introduction}

Thixo-forming allows alloys of various metals to be processed in semi-solid state. Using this process, steels can be treated as well, including the difficult-to-form types. Thixo-forming allows intricate-shape products with a good surface quality to be made, typically in a single forming step. However, technological difficulties have prevented thixo-forming of steels from gaining ground in industry. There are efforts to eliminate these difficulties. For instance, ASCOMETAL Group developed and patented a group of special low thixoforging temperature steels (LTT) [1, 2]. In these steels, the solidus temperature was reduced and the freezing range was expanded. By contrast, the authors of this study have succeeded in experimental processing of steel with $3.5^{\circ} \% \mathrm{C}$ and a very narrow freezing range at a processing temperature of approx. $1270{ }^{\circ} \mathrm{C}$.

Another incentive for processing in the semi-solid range is the potential for obtaining various types of microstructures. Unconventional microstructures can be obtained in conventional steels as well. Typical microstructures in thixo-formed steels consist of metastable polyhedral austenite embedded in a ledeburite network. Using a suitable modification to the steel chemistry, the microstructure configuration was inverted: hard globular carbides were embedded in more ductile austenite matrix $[3,4]$.

As the microstructure contains a larger amount of metastable austenite, the solidification rate and the rate of cooling from the semi-solid region are very important. High rates can be achieved in this process using its miniaturized variant: mini-thixoforming, which allows workpieces with volumes below $1 \mathrm{~cm}^{3}$ to be worked. The processes can be accelerated further by cooling the die. This speeds up solidification and has an effect on microstructure evolution. 


\section{Experimental programme}

Experimental material. Rapid cooling was tested in the experimental programme using CPM $15 \mathrm{~V}$ and CPM S30V steels (Tab. 1). They are powder metallurgy tool steels made with the use of the HIP process (Hot Isostatic Pressing). The selection of these steels was based on previous experience with designing chemistries and with calculations of chemical compositions suitable for semi-solid processing. For these calculations, phenomenological models built in JMatPro software were employed. With the CPM $15 \mathrm{~V}$ steel, the main criterion was to obtain a sufficient amount of vanadium carbides, a constituent with a melting point above $2800{ }^{\circ} \mathrm{C}$. They possess high thermal stability and are well suited for remaining in the newly-formed microstructure despite transition through semi-solid state. Thanks to high contents of vanadium, carbon, chromium and molybdenum, the material shows high wear resistance and hardness. Calculations conducted in the JMatPro software have revealed that although this material's freezing range is approx. $350{ }^{\circ} \mathrm{C}$, the liquid phase makes up $90 \%$ of its volume at a temperature as low as $1318^{\circ} \mathrm{C}$. This means that the temperature range available for forming is no more than $18^{\circ} \mathrm{C}$ (Fig. 1). Given this narrow temperature interval for processing, technical difficulties have to be overcome, particularly in terms of keeping the prescribed heating temperature.

Due to this fact, one additional steel was used for the experiment. It is the CPM S30V type (Tab. 1), which has lower carbon and vanadium levels than CPM $15 \mathrm{~V}$, while containing more chromium molybdenum. As a consequence, its freezing range is $138^{\circ} \mathrm{C}$ and its liquid fraction rises substantially more slowly (Fig. 1). Thanks to its microstructure, this steel, too, exhibits excellent wear resistance.

When

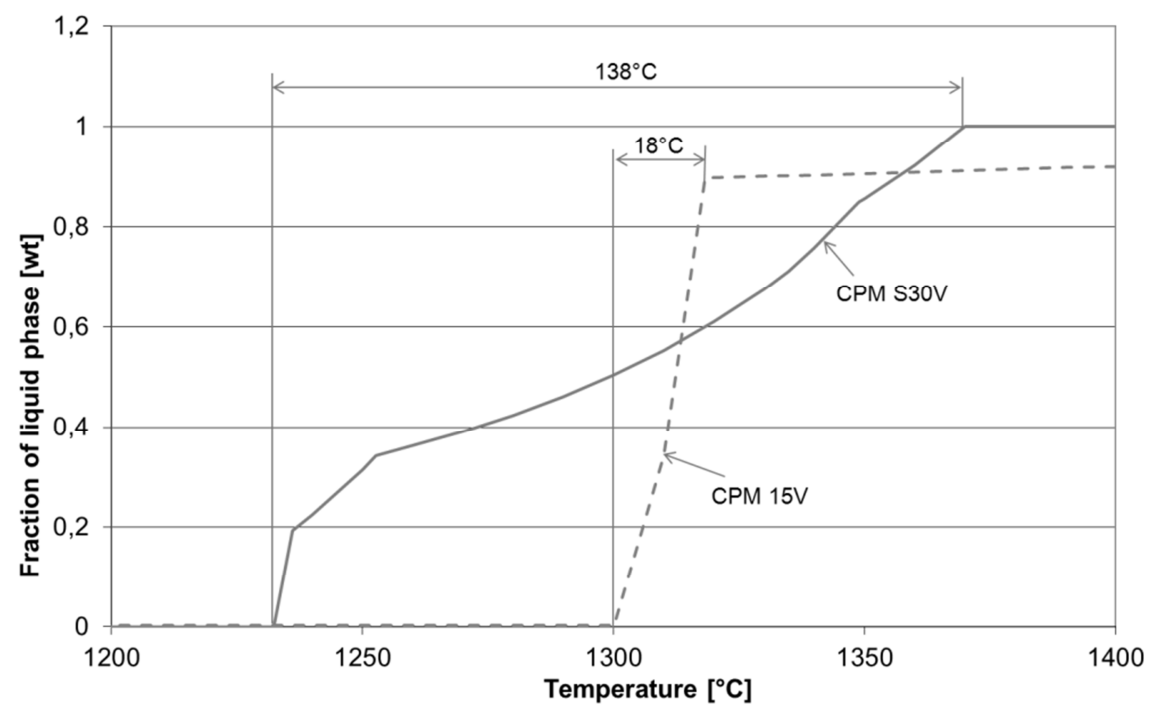

Fig. 1 Liquid fraction vs. temperature; according to calculation conventional processes are used, these steels are difficult to form and machine. In comparison with similar steel types, they even show a slightly poorer toughness.

Initial microstructures of both steels consisted of a ferrite matrix and uniformly dispersed carbides. EDS measurement of the CPM $15 \mathrm{~V}$ was used to measure its chemical composition and to identify its additional microstructure constituents: mostly vanadium and mixed carbides with sizes below $3 \mu \mathrm{m}$. Their content was found by X-ray diffraction analysis to be $28 \%$. Hardness of the material in this condition was $292 \mathrm{HV} 10$. In the microstructure of CPM S30V, mostly chromium and chromium-vanadium carbides were identified. Their size was 1-5 $\mu \mathrm{m}$. The total fraction of carbides was $31 \%$ and the hardness reached 310 HV 10.

Tab. 1 Chemical composition of CMP 15V and CMP S30V materials (wt. \%)

\begin{tabular}{|l|l|l|l|l|l|l|}
\hline & $\mathrm{C}$ & $\mathrm{Cr}$ & $\mathrm{V}$ & $\mathrm{Mo}$ & $\mathrm{Mn}$ & $\mathrm{Si}$ \\
\hline CPM 15V & 3.40 & 5.25 & 14.5 & 1.30 & 0.50 & 0.90 \\
\hline CPM S30V & 1.45 & 14 & 4 & 2 & & \\
\hline
\end{tabular}



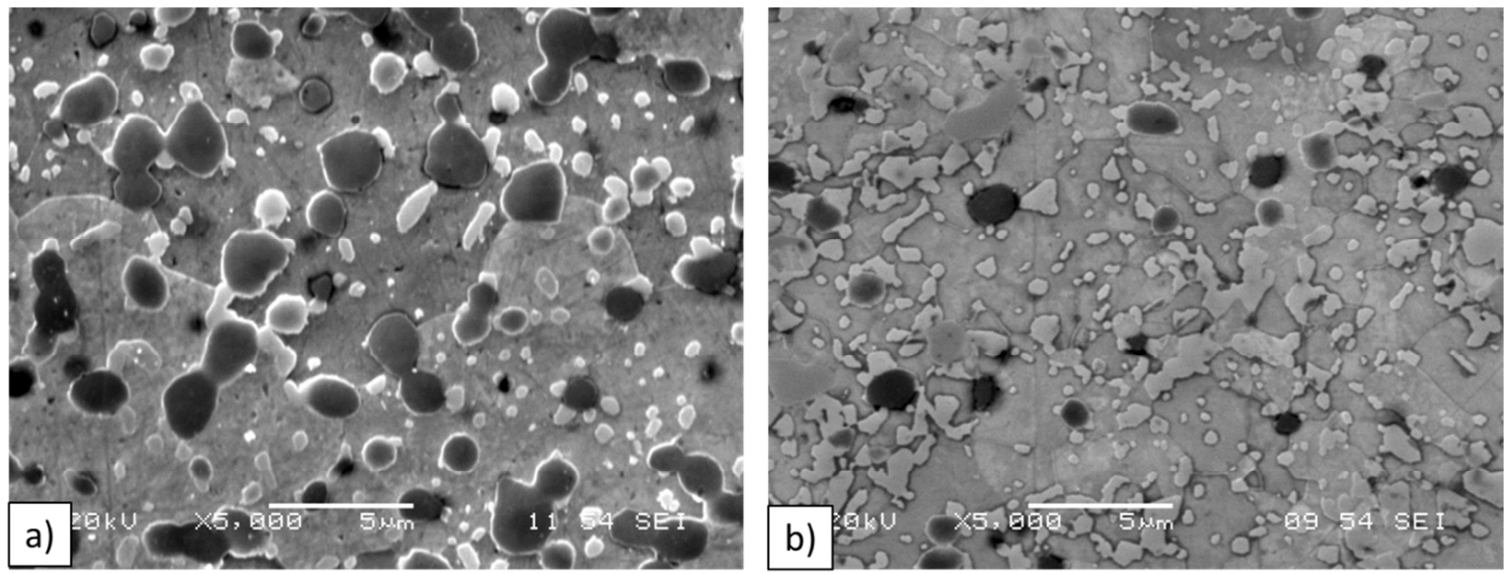

Fig. 2 Initial microstructure prior to mini-thixoforming: a) CPM 15V, b) CPM S30V

Mini-thixoforming. The semi-solid processing was undertaken using feedstock cut from sintered blocks. The workpieces were cylinders with $6 \mathrm{~mm}$ diameter and $46 \mathrm{~mm}$ height. The actual mini-thixoforming process involved lateral extrusion of material into a titanium die, which had been specially developed for this process [5, 6] (Fig. 3a). The pieces were heated in the die cavity using a combined electrical induction and resistance process. The heating temperature and forming parameters were obtained by stepwise optimization [3].

At the first stage of the experiment, the mini-thixoforming process was followed by solidification, wherein the workpiece was cooled by the die wall which was at room temperature prior to the experiment. For the second stage, the die was pre-cooled in liquid nitrogen (Figs. 3b, 3c) (Tab. 2). The die reached a temperature of $-196{ }^{\circ} \mathrm{C}$ in 8 minutes. The die temperature was measured using a type $\mathrm{K}$ thermocouple placed between the top and bottom parts of the die. The die was cooled with the workpiece inserted to cut handling times prior to forming to minimum. After the forming process, the final workpiece temperature was measured.
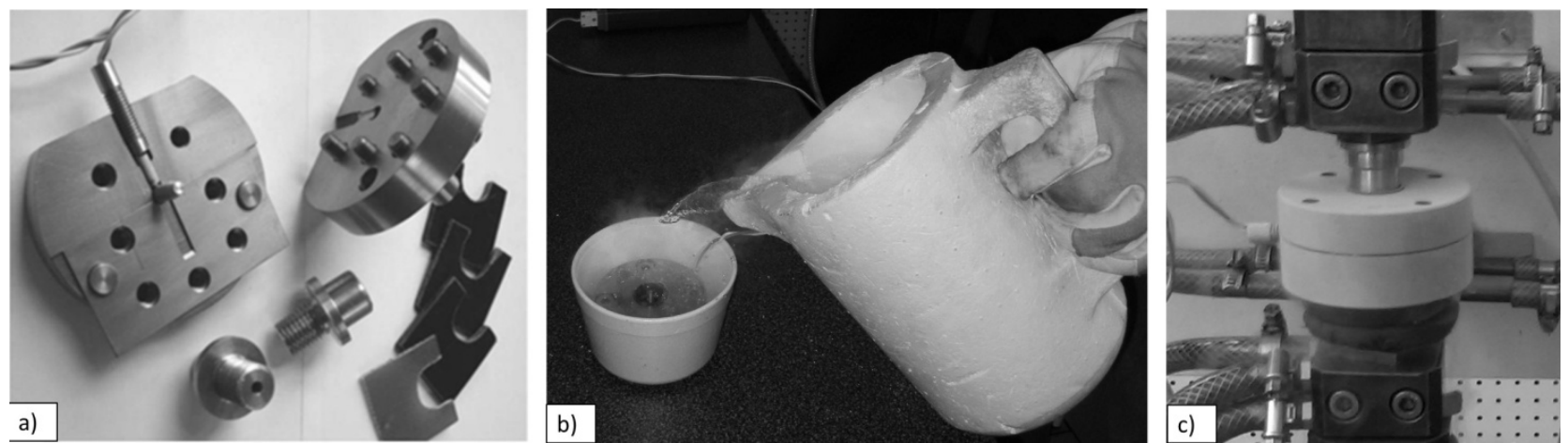

Fig. 3 a) Opened mini-thixoforming die, b) cooling the die with liquid nitrogen, c) mounting the die in thermomechanical simulator

Tab. 2 Results of semi-solid processing

\begin{tabular}{|c|c|c|c|c|c|c|c|}
\hline Steel & Condition & $\begin{array}{c}\text { Temperature after mini- } \\
\text { thixoforming }\left[{ }^{\circ} \mathrm{C}\right]\end{array}$ & $\begin{array}{c}\mathrm{HV} 10 \\
{[-]}\end{array}$ & $\begin{array}{c}\text { Carbide size } \\
{[\mu \mathrm{m}]}\end{array}$ & $\begin{array}{c}\mathrm{V}_{\gamma} \\
{[\mathrm{wt} \%]}\end{array}$ & $\begin{array}{c}\mathrm{V}_{\alpha} \\
{[\mathrm{wt} \%]}\end{array}$ & $\begin{array}{c}\mathrm{V}_{\mathrm{c}} \\
{[\mathrm{wt} \%]}\end{array}$ \\
\hline \multirow{4}{*}{$\mathrm{CPM} \mathrm{15V}$} & $\mathrm{IS}$ & - & 298 & 3 & & 72 & 28 \\
\cline { 2 - 7 } & $\mathrm{T}_{\mathrm{x}}-\mathrm{RT}$ & - & 657 & 2 & 50 & 29 & 21 \\
\cline { 2 - 8 } & $\mathrm{T}_{\mathrm{x}}-\mathrm{N}$ & -48 & 859 & 2 & & & \\
\cline { 2 - 8 } & $\mathrm{T}_{\mathrm{x}}-\mathrm{N}$ & -28 & 876 & 2 & & & \\
\hline \multirow{3}{*}{ CPMS30V } & $\mathrm{IS}$ & - & 310 & $1-5$ & & 69 & 31 \\
\cline { 2 - 8 } & $\mathrm{T}_{\mathrm{x}}-\mathrm{RT}$ & - & 468 & Carbide network & 70 & 14 & 16 \\
\cline { 2 - 8 } & $\mathrm{T}_{\mathrm{x}}-\mathrm{N}$ & -30 & 608 & Carbide network & & & \\
\hline
\end{tabular}

IS - initial state, Tx-RT - mini-thixoforming with die at RT, Tx-N - mini-thixoforming with die pre-cooled by liquid nitrogen 
Mini-thixoforming operations with a non-cooled and cooled die were performed using identical forming parameters. CPM $15 \mathrm{~V}$ steel was heated to $1270{ }^{\circ} \mathrm{C}$ over 56 seconds and then compressed with a reduction of approx. $8 \mathrm{~mm}$. Using optimization trials, it was found that the heating temperature for CPM S30V steel can be identical.

The cooled condition of the die affected primarily the process of cooling from the semi-solid state (Fig. 4). The cooling of the workpiece from the heating temperature to $200{ }^{\circ} \mathrm{C}$ in the noncooled die took 20 seconds. With the die pre-cooled by liquid nitrogen, the time required for cooling down to $200{ }^{\circ} \mathrm{C}$ was a mere 6 seconds. There is a great difference between the initial cooling rates, which occur in the region where carbides precipitate and the bulk of the microstructure develops. In the non-cooled die, the rate of cooling from $1270{ }^{\circ} \mathrm{C}$ to $800{ }^{\circ} \mathrm{C}$ was $177 \mathrm{~K} / \mathrm{s}$. In the die pre-cooled to $-196^{\circ} \mathrm{C}$ a rate of more than $1000 \mathrm{~K} / \mathrm{s}$ was achieved.

Metallographic techniques were used to assess the morphology, distribution and sizes of carbide forms and the nature of the matrix. Both optical and scanning electron microscopes were used. In addition, hardness was measured at various locations of the product. Fractions of microstructure constituents were found using X-ray diffraction analysis (diffractometer with a Co-K $\alpha$ source).

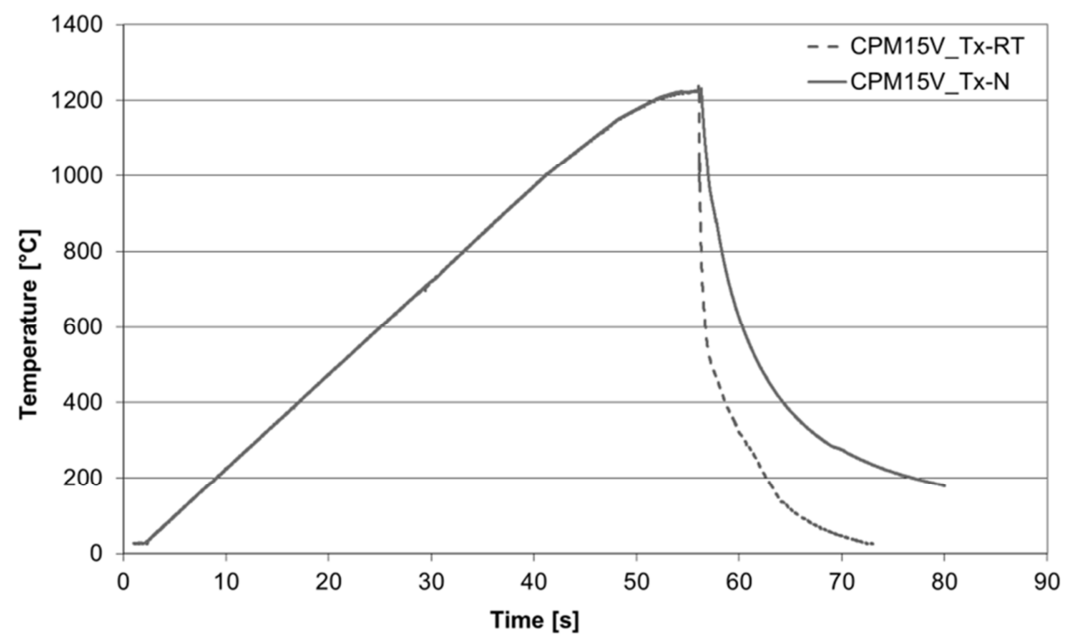

Fig. 4 Effect of die temperature on temperatures in processing CPM15V steel

\section{Results and Discussion}

Mini-thixoforming in Die at Initial Room Temperature. The mini-thixoforming process where the die was kept at room temperature prior to processing was employed for making oblong demonstration products from both steels (Fig. 5). The cross section of these products was $5 \times 3 \mathrm{~mm}$ and their length was $15 \mathrm{~mm}$. Their surfaces contained no visible defects.

Both steels were heated into the semi-solid region: $1270^{\circ} \mathrm{C}$. The transition through the semisolid state transformed their microstructures substantially. In the CPM $15 \mathrm{~V}$ steel, the ferrite matrix transformed into a mixture of austenite and martensite (Fig. 5). Martensite was present rather in the form of the M-A constituent within austenite grains. In this matrix, vanadium carbides with chromium remained. These were carbides with a higher melting point. Another constituent in the microstructure was chromium-vanadium eutectic which formed from dissolved chromium or chromium-vanadium carbides which were present in the initial material. The hardness of this constituent was $657 \mathrm{HV} 10$. Using X-ray diffraction analysis, the austenite fraction was found to be $50 \%$. With martensite and carbides they were $29 \%$ and $21 \%$, respectively. The size of carbide particles was approx. $2 \mu \mathrm{m}$.

The final microstructure of the CPM S30V steel showed different distributions and morphologies of microstructure constituents (Fig. 5). The base constituents included austenitic-martensitic matrix and carbides as well. As the chromium level was higher than that of vanadium, chromiumvanadium carbides prevailed in the initial microstructure and dissolved during the transition through the semi-solid state. Upon cooling, they formed a network of carbides and austenite, within which 
austenite grains containing martensite were embedded. The hardness of this microstructure was 468 HV10, lower than that of the CPM 15V material. The fractions of austenite, martensite and carbides were 70,14 and 16 per cent, respectively. Some vanadium carbides were detected as well, mostly within the carbide network.

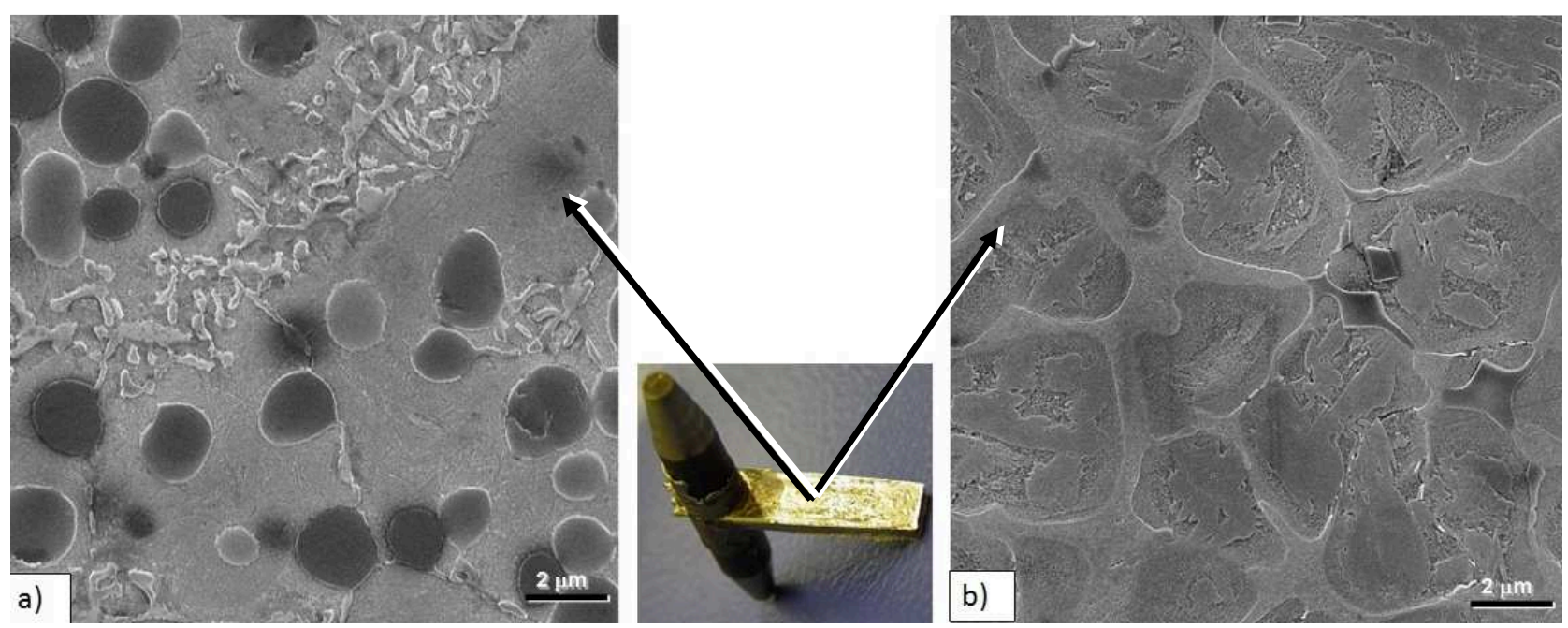

Fig. 5 Microstructures after mini-thixoforming with the die at room temperature before the process, a) CPM 15V, b) CPM S30V

Mini-Thixoforming in Die Pre-Cooled with Liquid Nitrogen. The parameters used were identical to those in the previous process, except the die temperature. The workpiece temperature was measured during semi-solid processing. At the end of the process, the workpiece temperature was between -48 and $-28^{\circ} \mathrm{C}$ (Tab. 2).

In the CPM $15 \mathrm{~V}$ steel, the cooling rate and the subzero final product temperature had a very notable effect. The microstructure consisted predominantly of martensite and dispersed vanadiumchromium carbides (Fig. 5). The hardness was considerably higher: 859 and 876 HV10 (Tab. 2). In the CPM S30V steel, the rapid cooling failed to prevent a carbide network from forming. The character of the resulting microstructure was very similar to that obtained with the conventional cooling method. The hardness, however, rose from the initial 468 to $608 \mathrm{HV} 10$. The material also contained austenite-martensite formations, within which the melt was enclosed, resulting in microscopic cavities.
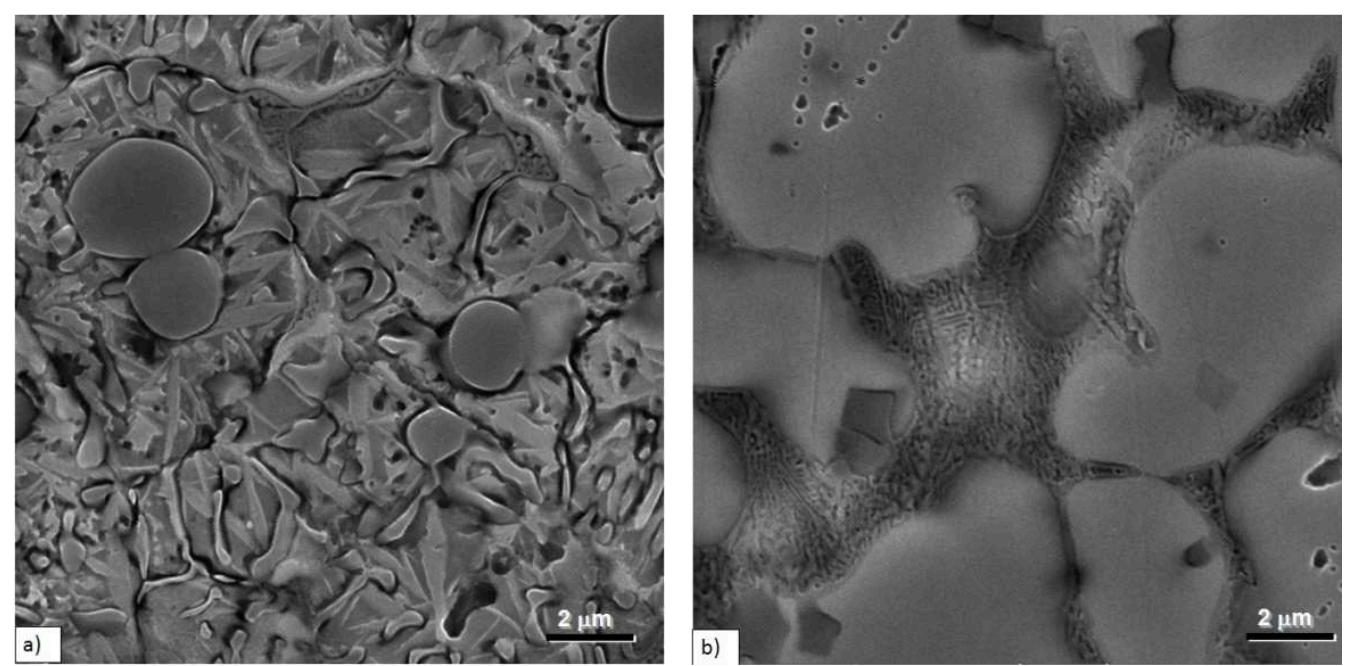

Fig. 6 Microstructures of materials mini-thixoformed in a die pre-cooled in liquid nitrogen, a) CPM 15V, b) CPM S30V 


\section{Summary}

An unconventional method of semi-solid processing was used for processing two steels. This mini-thixoforming experiment explored the effect of the solidification rate and cooling intensity on microstructure evolution. Two powder metallurgy tool steels were used for the experiment. These were high-abrasion-resistance CPM 15V and CPM S30V steels (Tab. 1). Solidification and cooling took place in a die at room temperature and in a die pre-cooled with liquid nitrogen (Fig. 3). Initial cooling rates of more than $1000{ }^{\circ} \mathrm{C} / \mathrm{s}$ were achieved in the pre-cooled die. In the die at room temperature, the cooling rate was approx. five times slower.

Using otherwise identical process parameters, the effects of cooling on microstructure evolution were mapped. It was found that transition through the semi-solid state leads to an interesting microstructure in CPM $15 \mathrm{~V}$ steel: austenitic matrix with some proportion of martensite and dispersed globular carbides (Fig. 5). With a higher heat dissipation rate due to the pre-cooled die, the proportion of martensite increased. This led to a higher hardness level of $880 \mathrm{HV} 10$, whereas the conventional technique with the die at room temperature resulted in a hardness of $660 \mathrm{HV} 10$. The CPM S30V steel had lower carbon and vanadium content. Its microstructure after minithixoforming consisted of austenite grains with embedded martensite. These M-A constituent grains were surrounded by a very fine carbide network. In this case, too, the higher cooling intensity was reflected in higher hardness. With the die at room temperature, the resulting hardness was $470 \mathrm{HV} 10$, whereas the use of the pre-cooled die led to a hardness in excess of $600 \mathrm{HV} 10$.

The experiment has proven once more the broad technological and microstructural potential of steels. As the results show, well-chosen combinations of unconventional processing and steels with appropriate chemistries may lead to rather unusual microstructure configurations.

Acknowledgement. This paper includes results created within the project P107/12/2600 "Effect of Forming in Semi-Solid State on Evolution of Microstructure of Powder Metallurgy Steels" and the project SGS-2011-056 "New Unconventional Materials Based on Iron and Vanadium Obtained by Rapid Solidification from Semi-solid State". The projects are funded from specific resources of the state budget for research and development.

\section{References}

[1] P. Cezard, T. Sourmail, Thixoforming of Steel: A State of the Art from an Industrial Point of View, Solid State Phnenomena. 141-143 (2008) 25-33.

[2] M. Robelet, A. Rassili, D. Fischer, Steel Grades Adapted to the Thixoforming Process: Metallurgical Structures and Mechanical Properties, Solid State Phenomena. 116-117 (2006), 712 716.

[3] H. Jirkova, et. al., Mini-thixoforming of a Steel Produced by Powder Metallurgy, Solid State Phenomena Vols. 192-193 (2013), 500-505.

[4] I. Sen, et. al., Microstructure and Mechanical Behaviour of a Mini-Thixoformed Tool Steel, Metallurgical and materials Transactions A 43 (2012), 3034-3038.

[5] B. Masek, D. Aisman, M. Behulova, H. Jirkova, Structure of Miniature Components from Steel Produced by Forming in Semi-solid State, Trans. Nonferrous Met. Soc. China. 20 (2010), 10371041.

[6] H. Jirkova, D. Aisman, B. Masek, Unconventional Structure of X210Cr12 Steel Obtained by Thixoforming, Journal of Alloys and Compounds. 504S (2010), 500-503. 